\title{
Evolving Tool Support for Digital Librarians
}

David M. Nichols, David Bainbridge, Gary Marsden*, Dynal Patel*, Sally Jo Cunningham, John Thompson, Stefan J. Boddie \& Ian H. Witten

Department of Computer Science, University of Waikato, New Zealand

*Department of Computer Science, University of Cape Town, South Africa

Keywords: Digital Library, Librarian's Role, Library Technology, Metadata 


\title{
EVOLVING TOOL SUPPORT FOR DIGITAL LIBRARIANS
}

\author{
Abstract \\ Usability in digital libraries is often focussed on end-user interactions such as searching and \\ browsing. In this chapter we describe usability issues that face the digital librarian in creating and \\ maintaining a digital library. The Greenstone digital library software suite is used as an example \\ to examine how to support digital librarians in their work.
}

\section{INTRODUCTION}

Usability in Digital Libraries (DLs) often concentrates on end-user interactions. In this chapter we describe the evolution of tools to support the other important class of DL user: the digital librarian.

As libraries have become more computerised librarians have had to learn more and more about computer systems, file formats and web servers. The Greenstone software development team has, over several years, developed a variety of tools to abstract away from these technical details to simplify the tasks of creating and maintaining digital collections.

Tasks supported by these tools include: collection creation, metadata assignment, collection interface design and multilingual interface support. We outline the history of Greenstone, the role of the digital librarian and how the tools have evolved to meet the needs of Greenstone's users.

\section{BACKGROUND}

Greenstone is a tool to simplify the construction of digital libraries (Witten, Boddie, Bainbridge \& McNab, 2000; Witten \& Bainbridge, 2003). As with many tools, it hides the complexity of the task from its users. A digital library can be understood at several levels, from a sequence of ones and zeroes to a whole library: as tool designers the problem we face is which levels are appropriate for user interaction. As Greenstone has developed and the user base has expanded the tools have changed to more easily support the work of digital librarians.

Discussions of usability and digital libraries (e.g. Borgman, 2003; Blandford 2001; Keith, Blandford, Fields \&Theng, 2002) usually focus on the end-users - the users that search the collections for information. The influence of DL creation tools on user studies is rarely discussed, yet the tools completely delimit the possible experiences of the information searchers. If the digital librarians find their tools hard to use then they are unlikely to be able to produce high 
quality DLs. The problem for the Greenstone developers is thus much harder: design Greenstone so that digital librarians can use it to produce easy-to-use digital libraries.

The earliest versions of Greenstone contained content-based abstractions, such as documents and collections, that are drawn from library and information science (LIS). These concepts have remained relatively static throughout Greenstone's development. In contrast the DL creation tools have evolved through several versions; largely to enable collection creators to work without using low-level command-line interaction. As the tools have improved the usability of the software we have observed more institutions and individuals using Greenstone as a vehicle to digitally publish their content.

\section{THE ROLE OF THE DIGITAL LIBRARIAN}

[A digital library is] a collection of digital objects, including text, video, and audio, along with methods for access and retrieval, and for selection, organization and maintenance of the collection. Witten, Bainbridge \& Boddie (2001, p. 96)

This definition of a digital library shows both the end-user side (access and retrieval) and the librarian side (selection, organization and maintenance). Although most user-oriented research on DLs focuses on the end-users, we concentrate here on the role of the digital librarian (Hastings \& Tennant, 1996). Although the term 'digital librarian' is gaining in currency the scope of associated skills is not yet well defined. A typical operational definition is that a digital librarian is a "type of specialist information professional who manages and organizes the digital library" (Sreenivasulu, 2000, p. 12).

Analysis of recruitment trends in LIS confirms that computer-based skills are in greater demand although few organisations are explicitly hiring 'digital librarians': "the evidence points to an increasingly and a rapidly changing automated library environment" (Marion, 2001, p. 148). Librarians have used computers to power online catalogues for many years but, as with other professions, computerisation has now become pervasive for both library staff and library users.

Although their environment is computerised the core mission of librarians, providing access to information, remains the same (Rice-Lively \& Racine, 1997). Greenstone itself is an example

of the increasingly computerised environment of the LIS professional and as such has to bring the technology of DLs to digital librarians in a format that doesn't require extensive knowledge of computers. 
Although the computerisation of the librarian's role is an important trend there is a further consideration: the empowerment of end-users to become digital librarians. As tools become more sophisticated the range of people wishing to publish information widens. In the case of Greenstone this trend is particularly relevant to our work in developing countries, "in particular by the observation that effective human development blossoms from empowerment rather than gifting ... a more effective strategy for sustained long-term development is to disseminate the capability to create information collections rather than the collections themselves" (Witten et al., 2001, p. 94). This view of DLs looks forward to a future where any user can be a digital librarian - when supported by appropriate tools. Greenstone supports this vision since, as open source software, it is freely downloadable by anyone from http://greenstone.org.

\section{TOOLS FOR DIGITAL LIBRARIANS}

Publishing a Greenstone DL involves several steps including: interface design and collection creation which covers source data specification, metadata assignment, and collection design. In this section we describe graphics tools for performing these two activities.

\section{Supporting Collection Creation}

Collection creation is the cornerstone to the Greenstone toolkit: it turns a number of source documents into a DL with browsing structures and full text searching, all accessible via a web browser or served in the exact same format from CD-ROM. Decisions made during this creative stage dictate what functionality is available to the end-user and how much effort is expended by the digital librarian in maintaining and extending the collection.

In Greenstone, the structure of a particular collection is determined when the collection is set up. This includes such things as the format, or formats, of the source documents, how they should be displayed on the screen, the source of metadata, what browsing facilities should be provided, what full-text search indexes should be provided, and how the search results should be displayed. Fundamentally, all this is expressed through configuration files and by executing command-line programs. In the early days of the software this was the only way to control the creation process, and typically required the involvement of staff with programming skills to establish a new type of collection. Once this had been done, adding new documents became a mostly pedestrian chore - so long as they have the same format as the existing documents, and 
the same metadata is provided, in exactly the same way — and could be conducted by someone with less specialist computer skills

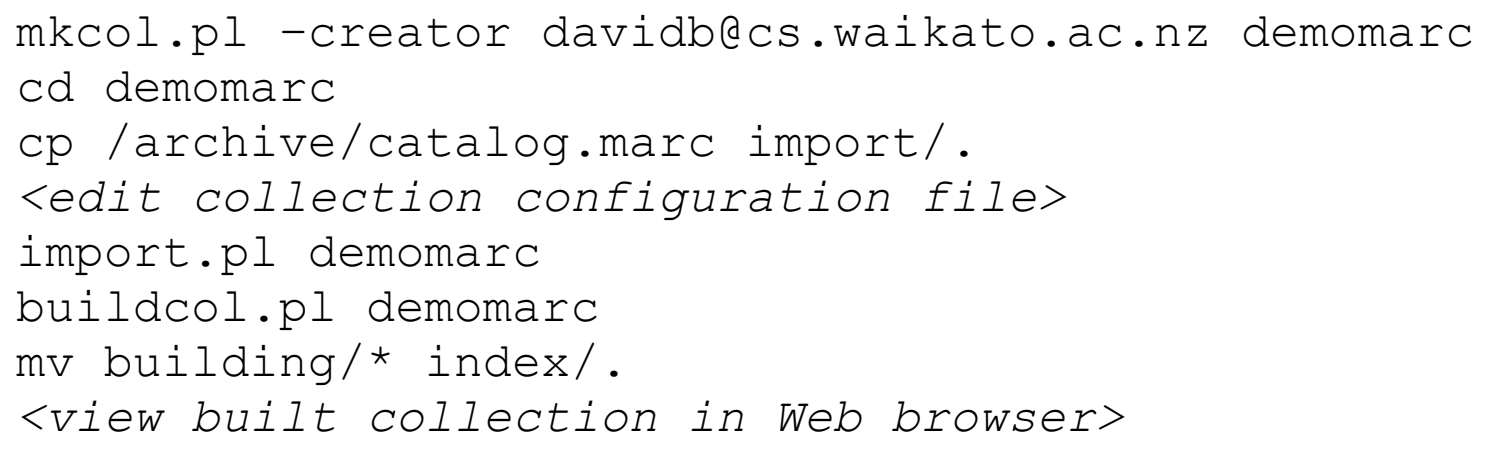

Figure 1. Typical command-line sequence to build a Greenstone DL

Figure 1 shows a typical command-line sequence for building a Greenstone DL: this contrasts sharply with the more supportive graphical environments used for most everyday computing tasks.

As unsightly as Figure 1 may appear, much of the excruciating, sometimes character-bycharacter specific, detail is masked by the entry $<$ edit collection configuration file $>$. Figure 2 reveals some of this detail, which is an excerpt from a collection configuration file for a DL based on MARC records. The extract shows that the collection creator has to specify many textual elements using syntax that many LIS professionals, and ordinary users, find difficult to use. The 'classify' statements produce browsing indices; they use pattern matching called regular expressions (the sequences of punctuation) to identify which items to include. The 'format' statements mix HTML elements and conditional programming constructs to determine how items in lists should appear.

Editing highly structured text files is error-prone and even experienced users can easily make mistakes. It is not surprising that many of the requests to the Greenstone mailing lists are for help with aspects of the collection configuration files. The command-line-based interaction was also awkward for users and usability testing showed that a structured web-based alternative was more effective (Nichols, Thomson \& Yeates, 2001). These tests compared the standard interaction with an early version of the web-based tool, The Collector; later versions are shown in Figures 3 and 4 . The Collector provided a more supportive environment for collection creation 
through making the sub-tasks an explicit part of the interface; always present and constantly reminding the user of the current state (Witten et al., 2001).

The Collector is modeled after popular end-user installation software (such as InstallShield). Frequently called a software 'wizard', this interaction style suits less technicallyadept users because it simplifies the choices and presents them clearly. The Collector is accessed via a web-browser and allows a point-and-click style of interaction to create a new DL collection.

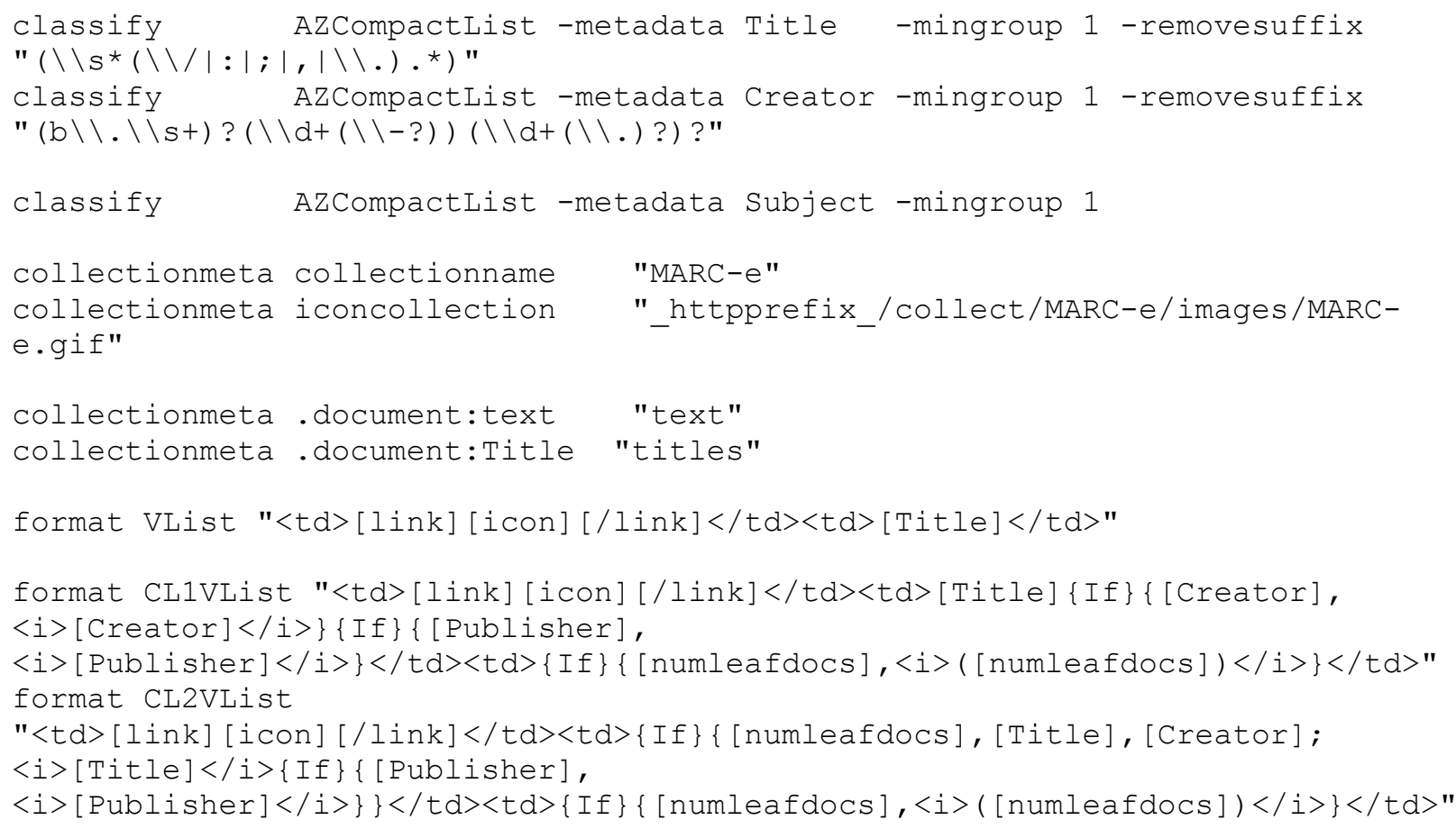

Figure 2. An extract from a collection configuration file for a DL collection of MARC records

Figure 3 shows an example snaphot of The Collector in use. Styled after the commonly encountered "wizard" helper applications — a term we try to avoid due to its appeal to mystcism and the unexplained - the digital librarian is guided through a sequence of steps, manifest as web pages, that control the building process. First the user specifies some top-level collection information such as its name, a contact email address and some text describing the focus and purpose of the collection. Next they enter the location of the source documents, which can be both local filenames and URLs to remote sites.

The third page presents the collection configuration file, initially seeded with some meaningful defaults, in a text box that can be freely edited. Once the user is statisfied with this they proceed to the building page, where the necessary Greenstone commands are run, including 
those necessary to amass all the source documents into one pace. Every five seconds or so this page is updated with the most recently generated text message output by the command line programs, so the digital librarian can monitor progress. The final stage of The Collector is viewing the built collection.

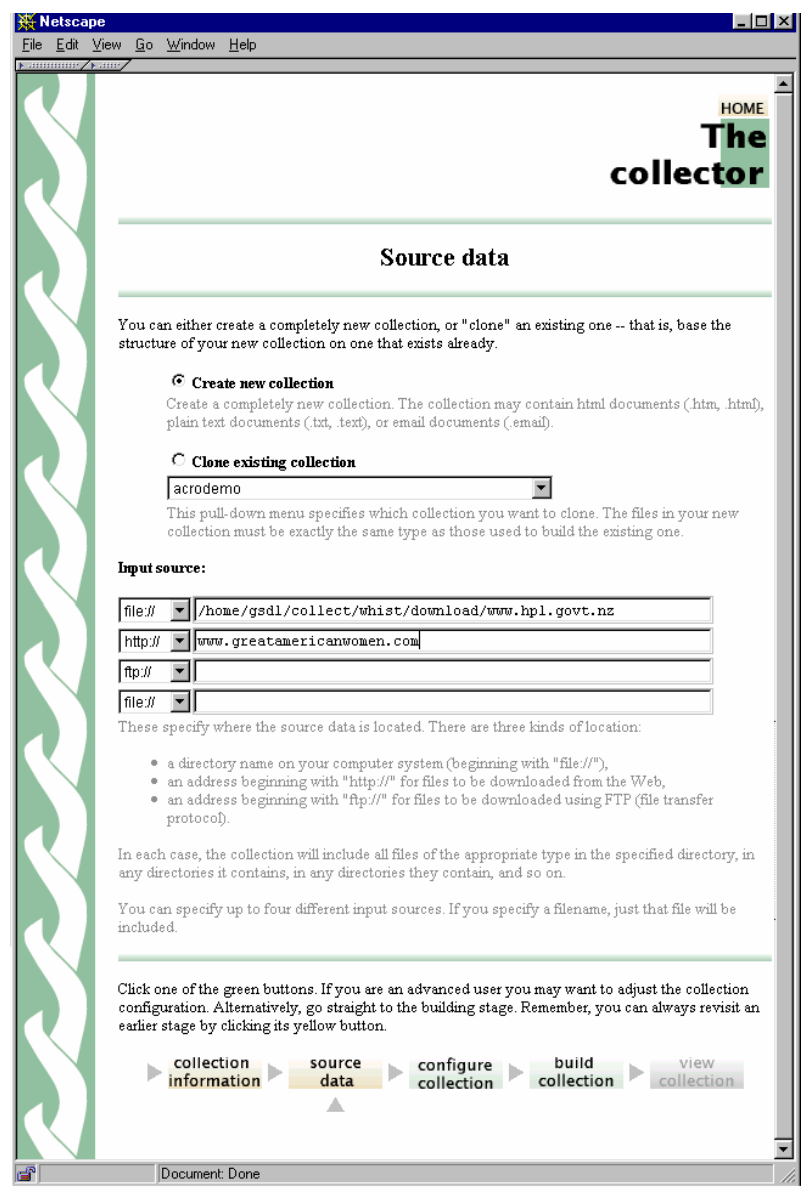

Figure 3. Specifying source data in The Collector

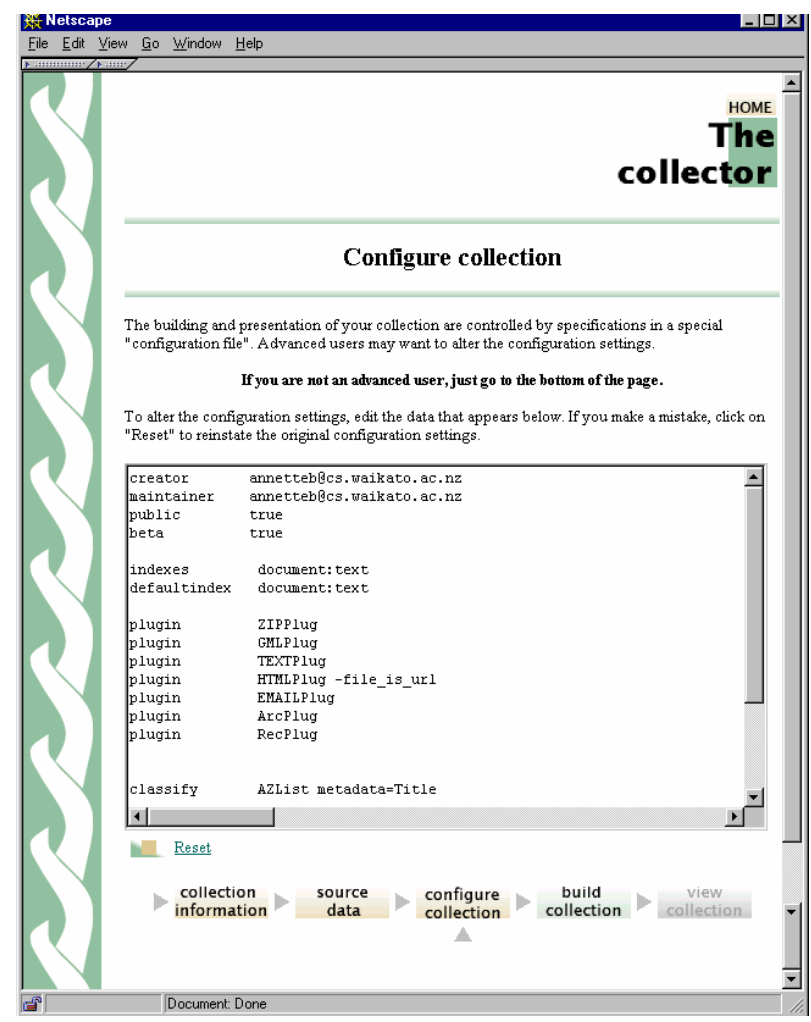

Figure 4. Collection configuration in The Collector

A progress bar at the bottom of every page maps where the digital librarian is within this five step progess. Once the collection is built, there are other sequences the librarian can choose from in addition to 'start a new collection'. These are: edit an existing collection, add new documents, and delete a collection.

The aim in developing The Collector was to support the activity of users building modest collections - both in size and complexity - and in this it was successful. Its key attributes are that is substantially lowers the entry cost for someone wanting to learn about collection creation and, by being implemented through web forms that are installed as part of the standard Greenstone installation, it is easy to access. 
Predictably, as users became more expert with the web tool, they encountered its limitations and requests started appearing for additional features. Beyond these feature additions, a more fundamental issue in The Collector is the exposure of the collection configuration file in its raw form. The message at the bottom of the page even says this is for advanced users, and most will probably want to skip on to the next page.

One of the most beneficial aspects of The Collector has proved to be the 'clone' feature. When a new collection is started, the user can either chose the default collection configuration file, or name an existing collection they want to base their new collection on. This allows for the possibility of a user working with, say, MARC data, seeding the collection configuration settings for their new collection from one that someone else has already developed for a similar purpose.

\section{The Organizer}

One of Greenstone's early adopters, SimpleWords of Brasov, Romania, developed The Organizer to assist in the assembly of collections for humanitarian purposes - collections that share a common collection configuration file but have different content. It relies on a substantial amount of metadata that must be manually assigned to each document in the collection. The utility, written using Visual $\mathrm{C}++$, runs standalone and is well tuned for its intended aim.

While The Organizer overcomes the main impediment of command-line only interaction, its tightly focused aim led to some design decision that are too restrictive when a wider audience for collection creation is taken in to account.

For instance, it is implicitly limited to a particular document model, and users who wish to add metadata not included in this model would have to make manual modifications to the Organizer's results. Also, because it is restricted to Windows, whereas Greenstone runs under Unix and MacOS X too, the Organizer is not fully integrated but works by generating intermediate files that Greenstone uses when building collections. While this loose coupling has some advantages in flexibility, it prevents the full collection-building process from being a single, integrated, task.

\section{Mercy Corps Case Study}

The Mercy Corps, an international relief and development organization with programmes in over 30 countries and reaching over 5 million people, has developed a "Metadata Creator" as a support tool for their digital librarian (Figure 5). The Mercy Corps uses Greenstone to organize 


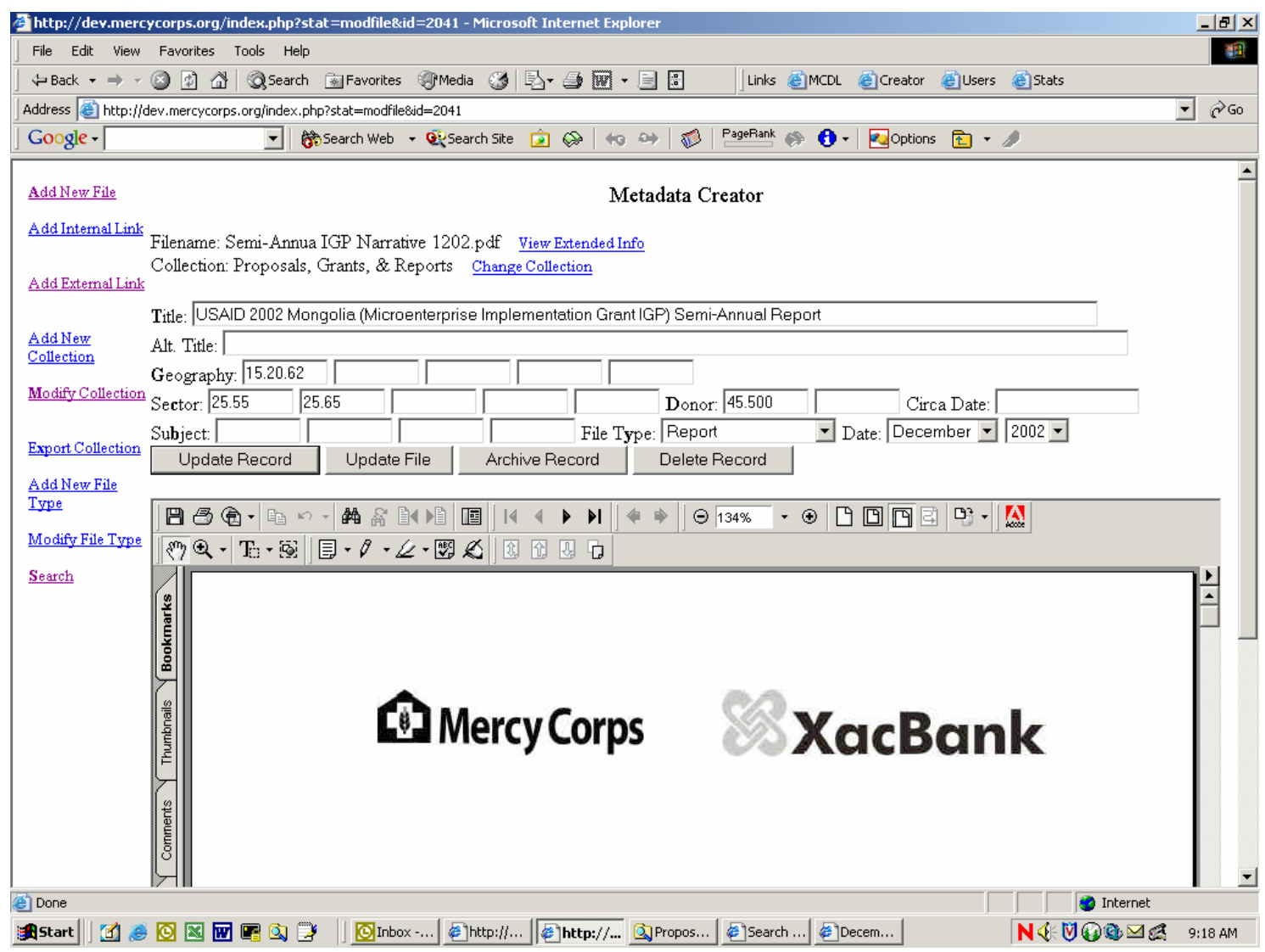

Figure 5. Metadator Creator from Mercy Corps

and make available to worldwide Corps workers and consultants a variety of in-house documents, including forms, reports, proposals, and manuals. Externally produced Web documents can also be indexed and included in a collection. The Metadata Creator supports collection maintenance through the full lifecycle of individual documents - from acquisition and addition of a document to the appropriate Greenstone collection(s), to recording updates or modifications to documents, to the removal and/or archiving of obsolete documents.

New documents are submitted for consideration for inclusion in the collection in one of two ways: either by a member in a field office who uses a simple web-based form to suggest metadata for the document, or — more usually — by the document creator emailing the document to a 'drop box' address. In either case, the digital librarian supervises the workflow from that point, using the Metadata Creator. The new document is manually checked for correctness, the librarian determines the appropriate collection(s) to which it should be added, and the document's metadata is created. The new document is then made available to users with internet access after 
the nightly automatic rebuild of the collections; users with poor internet connections receive an updated copy of the collections on CD, distributed periodically.

The usability of the Metadata Creator was significantly enhanced by an extensive, cooperative design effort, conducted through focus groups whose members included the digital librarian, a software developer, and potential users of the digital library. Some of the design tweaks suggested by the focus groups sound minor, but have had a major impact on the usability and acceptance of the system: for example, ability to view the document contents within the Metadata Creator (see the bottom portion of Figure 5) enables the digital librarian to quickly and easily scan the document when creating metadata, without leaving the Metadata Creator environment. Other changes have taken into account local insights into the types and contents of documents that will be included in Mercy Corps collections, such as that each document will always have a readily distinguishable title — and so the Title metadata should logically be filled in first, with the cursor focus initialized to that slot in the Creator form. The Mercy Corps experience provides strong evidence for improved usability of digital librarian tools through a design process that includes as broad a range of digital library stakeholders as possible.

\section{The Librarian Interface}

The lessons from the Organizer and the Mercy Corps Metadata Creator are that the standard Greenstone mechanisms for collection design and metadata assignment were not meeting the needs of our users. This feedback from our user community prompted the development of an improved environment for these elements of collection creation with Greenstone DLs (Bainbridge, Thomson \& Witten, 2003).

The Librarian Interface is our latest endeavour to support the digital librarian, see Figures 6 and 7. It encompasses the culmination of what we have learnt developing and reviewing other tools. The Librarian Interface (whose internal project name had been The Gatherer, a term which appears in some previous published work) allows users to collect sets of documents, import or assign metadata, and build them into a Greenstone collection. It differs from the Collector in that its default behaviour is to work on the computer running the Greenstone digital library software rather than building collections on a remote machine, and this permits a more flexible interface. It differs from the Organizer and the Metadata Creator in that it deals with unrestricted metadata sets, and can be tightly integrated with the Greenstone collection design and creation process. 


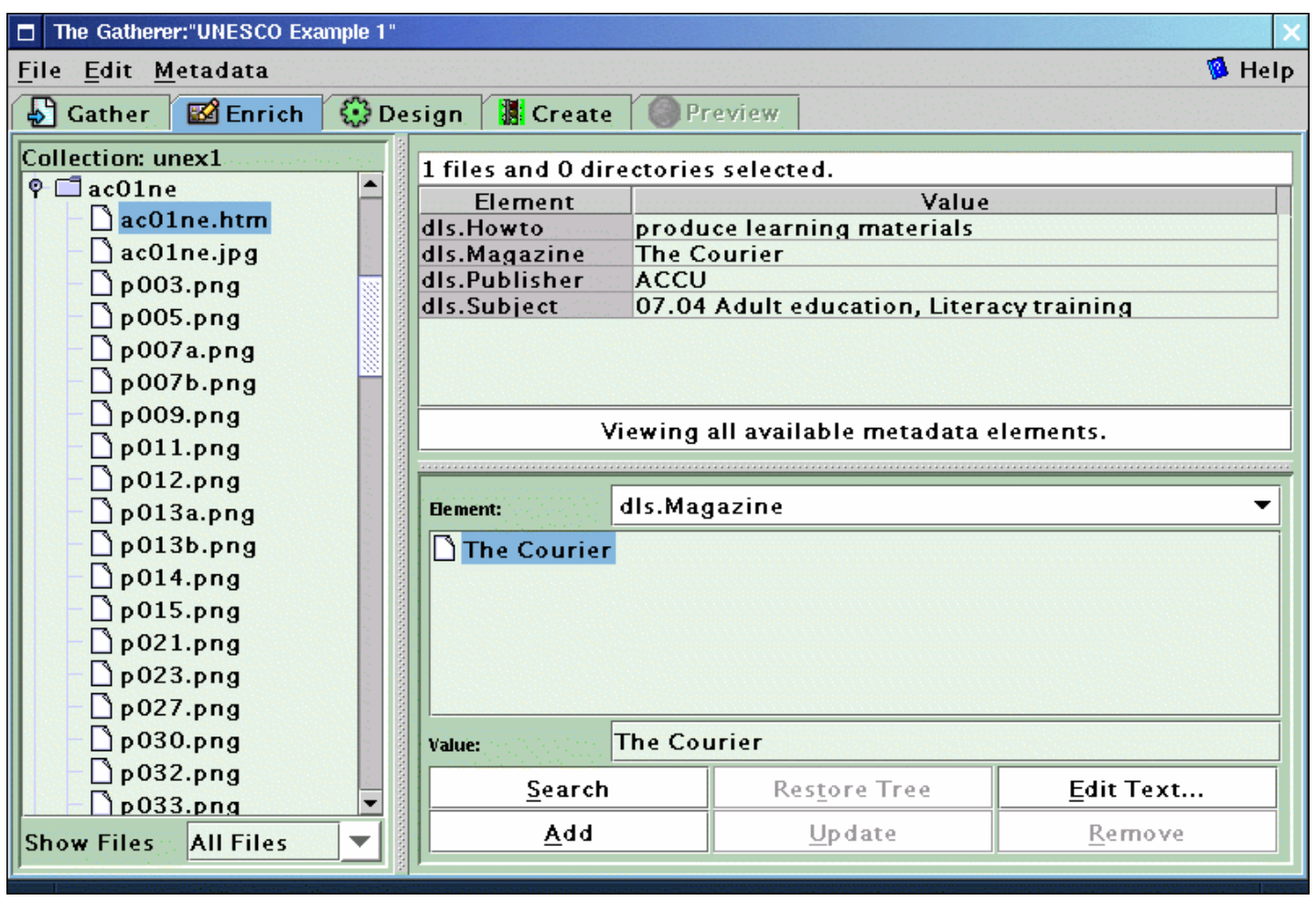

Figure 6. Assigning metadata using the Enrich view of The Gatherer

The Librarian Interface shares the more supportive environment of these three tools, taking elements from all three to provide the digital librarian with an integrated tool. The change of technology to a Java application also enables The Gatherer to have a more responsive interface and a richer graphical environment. The Librarian Interface is written in Java to help promote cross-platform independence and, with all textual user interface fragments stored in a languagespecific dictionary, support multilingual interfaces. It can be configured to run as standalone application, or through Signed Applets, over the Web.

Figure 6 shows the 'Enrich' view of The Gatherer where a digital librarian can assign metadata to objects inthe collection. In Figure 7 the user has clicked the Design tab and is reviewing the general information about the collection, entered when the new collection was created. The panel replaces editing of the raw configuration file. On the left are listed the various facets that the user can configure: Indexes, Subcollections, Languages, Plug-ins, Classifiers, Format Settings, and Metadata Sets. Appearance and functionality varies between these components of the tool. For example, clicking the Plug-in button brings up a screen that allows you to add, remove or configure plug-ins, and change the order in which the plug-ins are applied to documents. Importantly it shows the user a complete list of plugins that are available, and for 


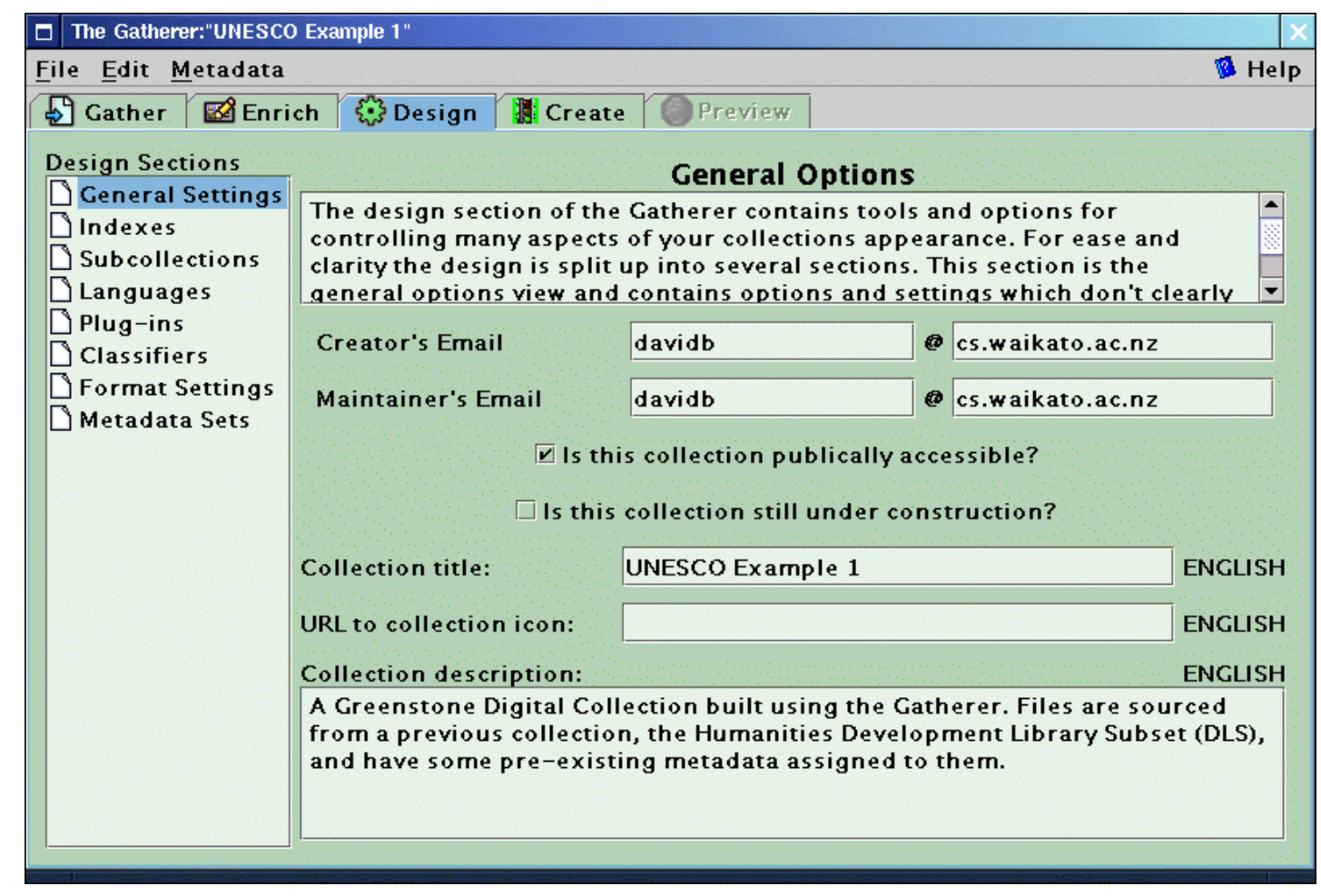

Figure 7 Designing a collection using The Gatherer

each plugin in the options that are supported. This differs from the environment of editing the raw configuration file where the user is simply expected to know what plugins and options exist. The same distinction occurs for classifiers and others features of the system.

\section{Supporting Interface Design}

Traditionally customising Greenstone's user interface required librarians to be familiar with Greenstone's architecture and internal workings. To change the look and feel of Greenstone's user interface librarians were required to manipulate a number of configuration files such as collection configuration files (see Figure 2), macro files and site configuration files. This required mastering the various commands and options that are available. In addition to this librarians were required to be competent web designers with good HTML skills. While a number of librarians were able to take on the steep learning curve and acquire the necessary skills to create a multitude of creative digital library sites, the majority were unable to tap and exploit the true power of the Greenstone Software. This is especially true in developing nations, where the levels of computer literacy are low requiring an even greater effort to acquire the skills necessary to customise Greenstone. 
It soon became obvious that if librarians were to harness the power of Greenstone software they would need to be able to tailor it to accommodate their individual needs and preferences. This view is consistent with a general consensus reached in 2002 at the CHI conference where the South African Development Consortium concluded that the best way to bridge the digital was to empower people with customisable software and not try to pre-empt the needs of particular users (Hugo, Marsden \& Walton, 2002). Customisation allows librarians to view information in a way that is relevant to a given collection, resulting in increased productivity and satisfaction.

However empowering librarians in this manner would require a solution that provides a complete abstraction from Greenstone's low level architecture. To support customisation, the solution would have to be flexible enough to cater for user needs and preferences. Furthermore, any functions, options or facilities offered by the solution would need to be visualised enabling the librarian to see what is customisable and where the boundaries and limits lie. In response to these needs, we embarked on a project to provide a tool that would provide this functionality.

One of the many unique features of Greenstone is its ability to publish collections on the internet or on CD-ROM. Providing such information in a structured digital version makes it available to a wider audience and reduces costs incurred in printing and distribution (Witten et al., 2001). However, these collections can only have profound benefits if the people that need this information most, are able to access it. Most people in developing countries are unable to access this information via the Internet. This is because gaining access to the Internet (and hence the collections) typically requires a PC and a land based telecommunication infrastructure (or network), both of which are rarities in developing countries. A more viable alternative distribution mechanism involves exploiting the current mobile telecommunications infrastructure in many developing countries.

Countries such as South Africa have almost double the number of mobile subscribers compared to landline subscribers. In $2002,92 \%$ of the South African population had access to a mobile network. Furthermore the end user devices (i.e. cell phones or GSM-enabled Pocket PCs) needed to provide wireless connectivity are becoming more affordable. Thus, providing wireless access to these libraries is an ideal solution for Africa as it has the potential to reach a wider audience, creating an opportunity for social and economic development.

With the notion of providing mobile access in mind, we developed a prototype system that performs two tasks. Firstly, as a high level customisation tool that allows librarians to tailor the 


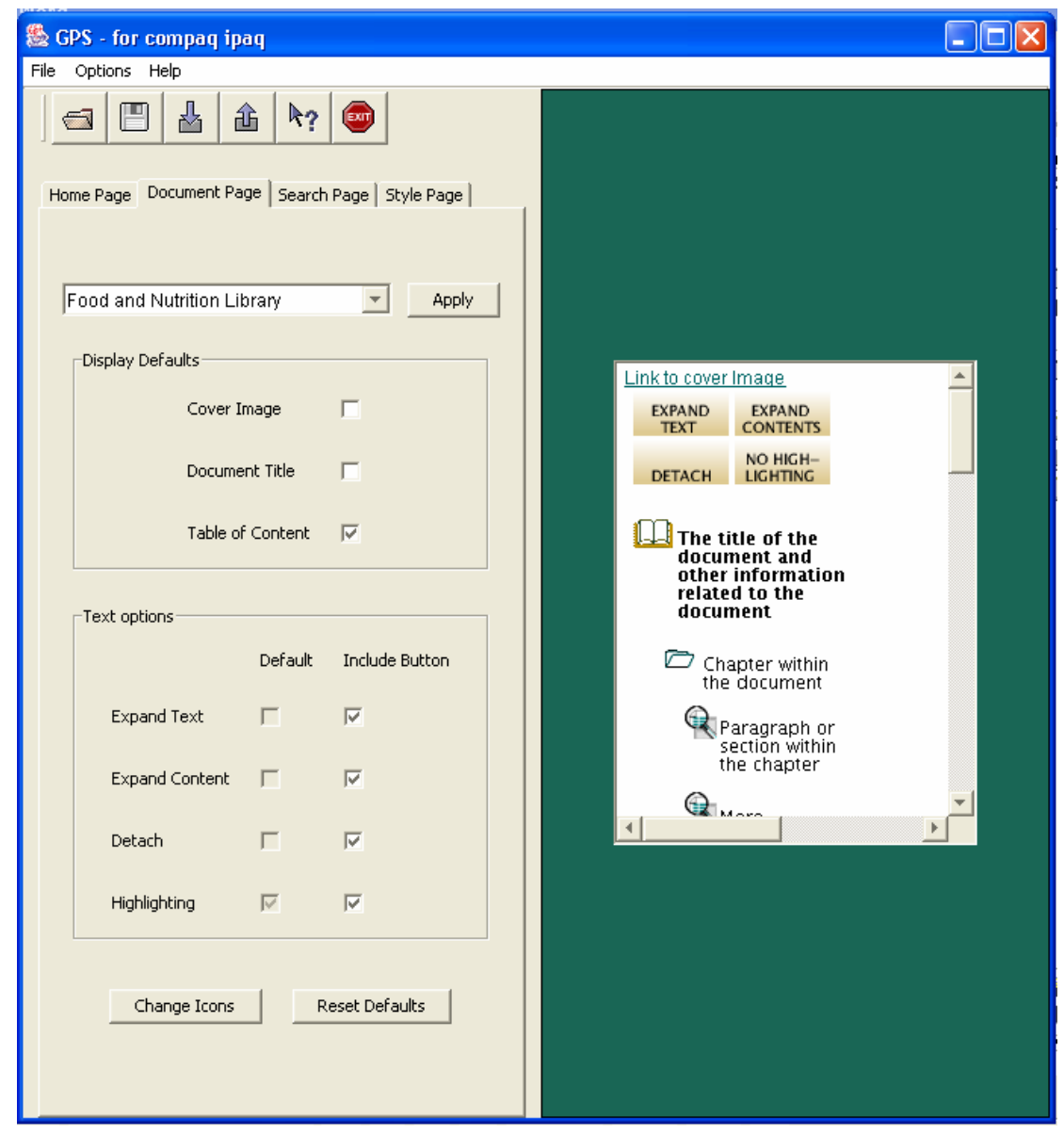

Figure 8. Customizing the Food and Nutrition Collection for the Compaq iPAQ Pocket PC

Greenstone site, and any available collections, using a graphical interface. Secondly, it allows librarians to create collections which can be accessed from a wireless PDA (personal digital assistant).

The resulting tool can be seen in Figure 8. The user can select the options they want to change and all user changes are visualised in a device window, providing dynamic feedback on the eventual appearance of the Greenstone site.

Figure 8 shows the options available under the 'Document Page' tab, on the left of the display. Users can choose to customise the Greenstone site for a specific collection (as in Figure 8) or for all collections. In this case the librarian has decided they only wish to publish one collection, that is the 'Food and Nutrition Library.' Furthermore, on the document page they have specified that they wish to have no cover image or document title, however they do wish to include a Table of Contents and all four document buttons. 
format DocumentImages false

format DocumentTitle false

format DocumentContents true

format DocumentButtons "Expand Text|Expand Contents|Detach|Highlight"

Figure 9. An extract from the collection configuration file for the 'Food and Nutrition Library'

In terms of Greenstone configuration files these options are selected or deselected by set generating the appropriate format statements. Figure 9 shows an extract from the 'Food and Nutrition Library' collection configuration file that corresponds to the settings in the Figure 8. Not only is it less intuitive to alter these values in a text editor, but to even find the correct file for editing would require considerable expertise on the user's part.

Similarly, the tool can be used to customise the look and feel of the home page of a document collection. Again the low level details are hidden from the users. For each page the librarian can set the default style by specifying document headers, footers, background colours, background images, text and link colours. For each available collection users are able to set a number of search preferences and can also customise how the search results are displayed. All user changes are visualised in the device window allowing the librarian to quickly prototype a desired design or solution. When the librarian wishes to apply the changes the tool generates configuration files that reflect user settings and are also optimised for the particular screen size setting. Once the configuration files have been generated, the Greenstone Digital Library is automatically restarted. The new configuration files are then processed to apply the changes and alter the DL's appearance.

Although this system is in its infancy, the power it provides has been recognised by several organisations. For example, HealthNet in Kenya are currently investigating its potential to provide medical information to doctors equipped with PDAs. Currently we are extending this system to provide customisation to future versions of Greenstone and support templates for different types of access device.

\section{FUTURE TRENDS}

Greenstone is open source software that is free to download and use (Witten et al., 2000); consequently the development team usually doesn't know who is using Greenstone unless they send a message to the mailing list. Typically these messages are requests for help or reports of possible errors with the software. As has been observed in other bug reporting systems (Nichols, 
Mckay \& Twidale, 2003) the precise nature of the problem often has to be clarified through a series of further messages between the developers and the user.

The distributed nature of Greenstone's usage and its non-expert users mean that it is difficult for the developers to obtain a clear idea of exactly how the software is used. One mechanism for addressing this developer-user gap is to simplify the reporting of problems while enhancing the contetxtual information of the report. We have developed a prototype system that adds user-driven error reporting to Greenstone (Nichols et al., 2003). The main features it provides:

- Integrating error reporting into the Greenstone system

- Allowing end-users to efficiently contribute their experiences to the software development team - Producing error reports that include more of the information the developers need to understand the user's problem

The deployment of this feature should widen the communication channel between the enduser, the digital librarians and the Greenstone development team. In turn, this increased participation will help to address the difficulties the developers face in obtaining usability information from a distributed user base.

In this chapter we have described how development efforts from third parties, Simple Words and Mercy Corps, have prompted the Greenstone developers to recognise limitations in the current system and suggested further enhancements to the software. The open source nature of Greenstone has facilitated this evolution for developers, but encouraging this feedback for typical end-users is a significant challenge for the future.

We anticipate further development of the existing Greenstone tools to provide a supportive environment for users to create DLs. In addition to improving existing tools we intend to add more tools to support other elements of the system. Greenstone can present DLs with many different interface languages (in additional to multi-lingual content) and maintaining consistency as the interface evolves is very complex. A new web-based tool manages the changes in these language interfaces, incorporating version control and allowing authorised users to contribute new translations of the interface text (Bainbridge, Edgar, McPherson \& Witten, 2003).

The current suite of tools in Greenstone doesn't yet reflect all of the facets of the job of the digital librarian that were discussed earlier. For example, the maintenance of a collection should be guided by the usage patterns of the end-users, but the tools to report on usage are less well 
developed than the other tools described in this chapter. However, the development of Greenstone is driven by requests from its users, so predicting the next stage of tool development is sometimes difficult.

The combination of all these developments aims to fufil Greenstone's goal, that everyone should:

participate actively in our information society rather than observing it from outside. It will stimulate the creation of new industry. And it will help ensure that intellectual property remains where it belongs - in the hands of those who produce it. Witten et al. (2001, p. 94)

Usability is key to achieving this goal of placing empowering DL technology in the hands of all computer users. In practical terms this means concealing irrelevant technical details, an increasing use of abstractions and the instantiation of those abstractions in easy-to-use tools.

\section{CONCLUSION}

Greenstone has developed several tools to enable non-technical users to access the power of DL technology. In this chapter we have reviewed some of the tools and described some of the usability issues we have encountered as the tools have evolved. A major challenge with software such as Greenstone is the globally distribution of its users and the increasing variety of contexts in which it is used. We see increased interaction between developers and users, at all stages of the software development lifecycle, as the only way to maintain the utility and usability of Greenstone.

\section{REFERENCES}

Bainbridge, D. Edgar, K.D., McPherson, J.R. \& Witten, I.H. (2003). Managing change in a digital library system with many interface language., In Proceedings of the 7th European Conference on Research and Advanced Technology for Digital Libraries (ECDL 2003) (pp. 350361). LNCS 2769. Berlin: Springer-Verlag.

Bainbridge, D., Thompson, J. \& Witten, I.H. (2003). Assembling and enriching digital library collections. In Proceedings of the $3 \mathrm{rd}$ ACM/IEEE-CS Joint Conference on Digital Libraries (JCDL 2003) (pp. 323-334). New York, NY: ACM Press.

Blandford, A., Stelmaszewska, H., Bryan-Kinns, N. (2001). Use of multiple digital libraries: a case study. In Proceedings of the First ACM/IEEE-CS Joint Conference on Digital Libraries (JCDL 2001) (pp. 179-188). New York, NY: ACM Press.

Borgman, C.L. (2003). Designing digital libraries for usability. In A.P. Bishop, N.A. Van 
House \& B.P. Buttenfield (Eds.) Digital Library Use: Social Practice in Design and Evaluation (pp. 85-118). Cambridge, MA: MIT Press.

Hastings, K. \& Tennant, R. (1996). How to build a digital librarian. D-Lib Magazine, 2(11) November 1996. Retrieved October 29, 2003 from http://www.dlib.org/dlib/november96/ucb/11hastings.html

Hugo, J., Marsden, G. \& Walton, M.(2002). CHI 2002 Development consortium: a South African perspective. SIGCHI Bulletin, 34(5), 4, 10.

Keith S., Blandford A., Fields B. \& Theng Y.T. (2002). An investigation into the application of claims analysis to evaluate usability of a digital library interface. In: A. Blandford \& $\mathrm{G}$. Buchanan (Eds.) Proceedings of the Workshop on Usability of Digital Libraries, 3rd ACM/IEEECS Joint Conference on Digital Libraries, Houston, TX.

Marion, L. (2001). Digital librarian, cybrarian, or librarian with specialized skills: Who will staff digital libraries? In H. Thompson (Ed.), Crossing the Divide: Proceedings of the Tenth National Conference of the Association of College and Research Libraries, March 15-18, 2001, Denver, CO. (pp. 143-149), Chicago, IL: American Library Association.

Nichols, D.M., Mckay, D. \& Twidale, M.B. (2003). Participatory usability: supporting proactive users. Proceedings of the 4th Annual Conference of the ACM Special Interest Group on Computer Human Interaction - New Zealand Chapter (CHINZ'03) (pp. 63-68). Dunedin, New Zealand: ACM SIGCHI New Zealand.

Nichols, D.M., Thomson, K. \& Yeates, S.A. (2001). Usability and open source software development. In E. Kemp, C. Phillips, Kinshuck, and J. Haynes (Eds.), Proceedings of the Symposium on Computer Human Interaction (pp. 49-54). Palmerston North, New Zealand: ACM SIGCHI New Zealand.

Rice-Lively, M. L. \& Racine, J.D. (1997). The role of academic librarians in the era of information technology. Journal of Academic Librarianship, 23(1), 31-41.

Sreenivasulu, V (2000). The role of a digital librarian in the management of digital information systems (DIS). The Electronic Library, 18(1), 12-20.

Witten, I.H. \& Bainbridge, D. (2003). How to Build a Digital Library. San Francisco, CA: Morgan Kaufmann.

Witten, I.H., Bainbridge, D. \& Boddie, S.J. (2001). Power to the people: end-user building of digital library collections. In Proceedings of the First ACM/IEEE-CS Joint Conference on Digital Libraries (pp. 94-103). New York, NY: ACM Press.

Witten, I.H., Boddie, S.J., Bainbridge, D. \& McNab, R.J. (2000). Greenstone: a comprehensive open-source digital library software system. In Proceedings of the Fifth ACM Conference on Digital Libraries (DL 2000) (pp. 113-121). New York, NY: ACM Press.

Witten, I. H., Loots, M., Trujillo, M. F. \& Bainbridge, D. (2001). The promise of digital libraries in developing countries. Communications of the ACM, 44(5), 82-85. 